\title{
BMJ Open Economic evaluation of a brief counselling for smoking cessation in dentistry: a case study comparing two health economic models
}

\author{
Suvi Erika Virtanen, ${ }^{1}$ Maria R Galanti, ${ }^{1}$ Pia M Johansson, ${ }^{2}$ Inna Feldman ${ }^{3}$
}

To cite: Virtanen SE, Galanti MR, Johansson PM, et al. Economic evaluation of a brief counselling for smoking cessation in dentistry: a case study comparing two health economic models. BMJ Open 2017;7:e016375. doi:10.1136/ bmjopen-2017-016375

- Prepublication history and additional material are available. To view these files please visit the journal online (http://dx.doi. org/10.1136/bmjopen-2017016375).

Received 9 February 2017 Revised 23 May 2017 Accepted 25 May 2017

\section{CrossMark}

${ }^{1}$ Department of Public Health Sciences, Karolinska Insitutet, Stockholm, Sweden

${ }^{2}$ Public Health and Economics, Stockholm, Sweden

${ }^{3}$ Department of Public Health and Caring Science, Uppsala Universitet, Uppsala, Sweden

Correspondence to

Inna Feldman; inna.feldman@ pubcare.uu.se

\section{ABSTRACT}

Objectives This study aimed to compare the costeffectiveness estimates of a brief counselling of smoking cessation in dentistry by using two different health economic models.

Design and outcome measures Intervention effectiveness was estimated in a cluster randomised controlled trial. The number of quitters was estimated based on 7-day abstinence and on smoking reduction at follow-up. Health economic evaluation was performed using two models: (1) a population-based model employing potential impact fractions and (2) a Markov model estimating the cost-effectiveness of the intervention for the actual participants. The evaluation was performed from healthcare and societal perspectives, and health gains were expressed in quality-adjusted life-years (QALYs).

Setting Dental clinics in Sweden.

Participants 205 Swedish smokers aged 20-75 years. Interventions A brief, structured behavioural intervention was compared with 'usual care'.

Results The cost per quitter was US\$552 in the intervention and US\$522 in the 'usual care' condition. The net saving estimated with the population-based model was US\$17.3 million for intervention and US\$49.9 million for 'usual care', with health gains of 1428 QALYs and 2369 QALYs, respectively, for the whole Swedish population during 10 years. The intervention was thus dominated by 'usual care'. The reverse was true when using the Markov model, showing net societal savings of US\$71000 for the intervention and US $\$ 57000$ for 'usual care', with gains of 5.42 QALYs and 4.74 QALYs, respectively, for lifelong quitters.

Conclusion The comparison of intervention and 'usual care' derived from small-scale studies may be highly sensitive to the choice of the model used to calculate costeffectiveness.

Trial registration The cluster randomised trial is registered in the ISRCTN register of controlled trials with identification number ISRCTN50627997.

\section{INTRODUCTION}

Despite continuously declining prevalence, cigarette smoking contributes to $7.5 \%$ of the burden of disease in Sweden ${ }^{1}$ and was estimated to stand for $6.7 \%$ of the national costs for healthcare and loss of production in $2001 .^{2}$

\section{Strengths and limitations of this study}

- The cost-effectiveness of a brief counselling for smoking cessation in dentistry was assessed using two different models: an individual-level Markov model and a population-based model.

- The comparison of the two models' estimates, due to different modelling assumptions, illustrates the importance of model choice.

- The non-significant differences in the effectiveness of the novel intervention compared with the control condition imply uncertainty of the subsequent economic evaluation.

- The uncertainty of the estimates is further increased by the assumptions made on long-term quit rates.

Quitting smoking substantially decreases the risk for its negative health consequences ${ }^{3}$ through a notable reduction in the risks for cancer, cardiovascular disease and diabetes. ${ }^{3-5}$

Healthcare providers in Sweden are encouraged to offer their patients support for smoking cessation. ${ }^{6}$ Optimally, such interventions should be of low intensity in order to be delivered as a part of the routine care. Due to the high proportion of the general population visiting dental care regularly and for the oral health consequences of smoking, dental clinics are a particularly suitable setting for the delivery of brief smoking cessation counselling. ${ }^{78}$ However, counselling in dentistry is currently underused and will remain so unless training of professionals and changes in the health system are introduced. ${ }^{9}{ }^{10}$ Health economic evaluations offer the possibility to compare interventions in terms of their costs and health effects, thus facilitating decision making.

Evaluations have so far confirmed the effectiveness and cost-effectiveness of smoking cessation interventions. ${ }^{11}$ Brief advice for smoking cessation has also been found cost-effective, ${ }^{12} 13$ but economic evaluations of such 
interventions in dental care are sparse. Cost-effectiveness estimates obtained from other healthcare settings may not apply to dentistry. In fact, among smoking patients seen in dental care, there is an over-representation of healthy individuals and light smokers not very motivated to quit. Also, dental care professionals and dental clinics' organisation may have lower capacity to address lifestyle factors compared with other healthcare settings, thus impacting on the delivery of preventive advice. One Swedish study conducted an economic evaluation of high- and low-intensity smoking cessation interventions in dental care, ${ }^{14}$ but because of their intensity, neither of these formats could be considered as brief advice. In summary, the knowledge about cost-effectiveness of smoking cessation interventions in dental care is incomplete. ${ }^{15}$

The majority of cost-effectiveness studies of smoking cessation treatments use mathematical modelling based on simulation techniques. ${ }^{16}$ Different models have been developed to reflect the influence of smoking and smoking cessation on future health risks. Bolin ${ }^{16}$ emphasised two types of models: the more common individual-level Markov models ${ }^{17} 18$ and the dynamic population-based simulation models that allow for the user to specify epidemiological details of the studied population. ${ }^{19}{ }^{20}$ Markov models are typically used to evaluate the cost-effectiveness of an intervention in a specific setting for the intervention's target group, while dynamic population-based models are often used to estimate policy impact on public health. The estimates obtained with these two approaches may differ, as may the implications for decision making.

In this study, we present a comparison of two cost-effectiveness estimates of a brief structured counselling for smoking cessation delivered in the context of dental care in Sweden, the effectiveness of which was assessed in a randomised controlled trial (FRITT study). ${ }^{21}$ The study was guided by the following research question: Does the estimates of cost-effectiveness of a brief counselling for smoking cessation in dentistry differ when estimated with a population-based model compared with an individual-based Markov model?

\section{METHODS}

The study was approved by the ethical review board of Stockholm Region, 15 March 2012 (no 2012/237-31/5). The participants were included in the study only after they had given written informed consent.

\section{The intervention}

The economic evaluation was conducted based on data from a cluster randomised controlled trial that compared brief counselling for tobacco cessation with usual care provided to Swedish tobacco users in dental clinics. ${ }^{21}$ The study is registered in the ISRCTN register of controlled trials with identification number ISRCTN50627997. The English translation of the original study protocol is available as see supplementary file 1 .
Briefly, 27 dental care clinics were randomised to either alternative intervention or control condition and recruited thereafter patients aged $18-75$ years who were daily tobacco users (figure 1). Follow-up was conducted 6 months after enrolment (97\% retention). All information was self-reported by the patients. Dental clinics were approached between May and August 2012. The training of personnel was delivered during September 2012. Patients were recruited between October 2012 and January 2013, and the 6-month follow-up was completed in November 2013. The intervention consisted of a structured brief advice based on the 5A's model delivered once during a dental visit performed by a dentist or a dental hygienist. The control condition implied delivering care as usual according to the clinic's routines, if any. Approximately half of the clinics in the control condition had personnel trained in tobacco cessation and routines concerning patients' tobacco use. All patients at intervention clinics and approximately $72 \%$ of patients at control clinics received some level of advice on tobacco use. However, counselling at intervention clinics was on average more extensive, including for instance information on available support and pharmacological treatment almost 10 times as often as on control clinics. While tobacco cessation advice, if received, lasted on average $3.5 \mathrm{~min}$ at the control clinics, the duration was $5 \mathrm{~min}$ longer (ie, $8.5 \mathrm{~min}$ ) at intervention clinics.

\section{The study sample}

In the main study, ${ }^{21}$ participants $(\mathrm{n}=467)$ consisted of current daily smokers $(n=218)$, current snus users $(n=200)$ and dual users of cigarettes and snus $(n=41)$. Due to the much less established burden of disease caused by the Swedish type of smokeless tobacco (snus), ${ }^{22}$ only data from smokers were used in the current economic evaluation. In addition, we restricted the analysis to individuals aged 20 years or older because the population-based model was limited to adult population 20-84 years old. There were 13 participants younger than 20 years, and none of these individuals changed smoking habits. Thus, the analytical sample from the effectiveness study on which the present economic analysis is based comprised 99 smokers in the intervention condition and 106 smokers in the control condition ('usual care').

When the analysis was limited to smokers, no statistically significant differences between intervention and control group were seen in any of the studied outcomes.

The primary outcome, 7-day point prevalence of abstinence, was defined as 'having smoked 0 cigarettes in the 7 days preceding the survey'. This condition was self-reported by $8 \%$ of participants both in the intervention and in the usual care condition. A secondary outcome entailing substantial tobacco reduction was calculated as reporting at follow-up an amount of cigarettes per day equal to or less than $50 \%$ of that reported at baseline. This reduction was achieved by $27 \%$ of participants in the intervention condition and by $17 \%$ in the comparison condition. 


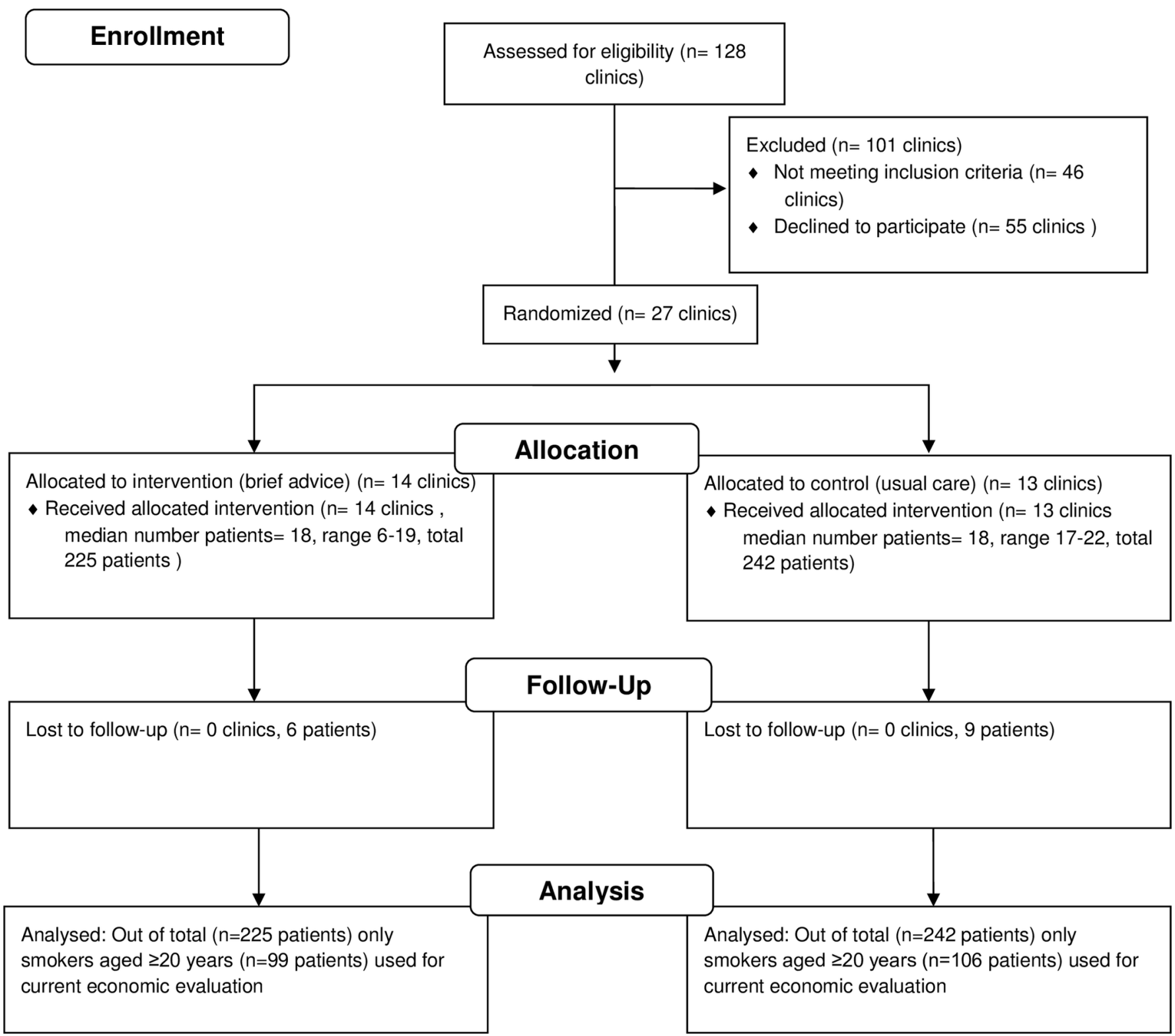

Figure 1 CONSORT flowchart. Enrolment, allocation and retention of participants.

\section{Economic evaluation}

We aimed to conduct an incremental cost-effectiveness analysis with long-term health effects. The alternative intervention was compared with 'usual care'. The costs and health effects were estimated according to the Swedish recommendations ${ }^{23}$ on economic evaluations of healthcare interventions. Therefore, costs were calculated from healthcare and societal perspectives, while health effects are expressed in quality-adjusted life-years (QALYs). The intervention under study was conducted in 2012; thus, the intervention costs as well as societal costs in the models were estimated in Swedish crowns per 2012. Furthermore, the costs were inflated to reflect 2014 costs according to the Swedish consumer price index ${ }^{24}$ and converted to 2014 US dollars using the purchasing power parity estimates with CCEMGEPPI-Centre Cost Converter (http://eppi.ioe.ac.uk/ costconversion/default.aspx).
Both costs and QALYs were discounted 3\% annually. Long-term costs and health effects were simulated using the two models to be compared:

1. A population-based simulation model employing potential impact fractions, where the intervention effect is assumed to change the incidence in tobaccorelated diseases, including diabetes mellitus type 2 , cardiovascular disease (CVD), chronic obstructive pulmonary disease (COPD) and seven cancer diagnoses, above all lung cancer.

2. An individual-level Markov model incorporating the decreased smoking-related risks for lung cancer, COPD and CVD.

\section{Intervention costs}

Only the costs connected with the delivery of the interventions were included in the analysis. The quantity of resources consumed was obtained from the study's 
accounting records. The unit costs were obtained from national public databases, from suppliers' websites and from the organisers of the training. Total intervention costs were obtained by multiplying the volume of each cost category by its respective unit cost. Intervention costs were divided into training and operating costs. The costs were not discounted because the interventions was delivered during 4 months.

Training costs for the brief advice included costs for salary and travel costs for the trainer, venue and materials, as well as allowance for training time for trainees (4hours per dental professional). Only $20 \%$ of the total costs were considered, in order to accommodate for the spread over a 5-year period before refresher training may be needed, as it was previously done in similar studies. ${ }^{25}{ }^{26}$ The number of patients who smoke, per dental care professional, was estimated based on the prevalence of smoking in Sweden ${ }^{27}$ and the average number of patients the practitioners in the trial reported seeing each year.

Operating costs represented the costs of delivering tobacco cessation counselling in intervention and 'usual care' conditions and were estimated based on the duration of the counselling and on average salaries including social charges.

Other costs connected with the interventions included patients' time in attending counselling, based on the mean duration of the counselling, and use of nicotine replacement therapy (NRT) or other medications for tobacco cessation. Costing of patients' time was estimated based on the opportunity cost of foregone leisure time and calculated at $25 \%$ of the Swedish average gross wage rate. ${ }^{28}$ The cost of medications was estimated based on the retail price of the most commonly used drugs and on the recommended duration of use.

To estimate the cost of the interventions if they were applied to the entire Swedish population, we estimated the number of daily smokers who visit dental clinics during a year. The number of smokers was obtained from national surveys, ${ }^{27}$ as was the number of adults visiting dental care each year. ${ }^{6}$ Each year, 449000 smokers were estimated to visit dental care.

\section{Estimate of intervention effectiveness}

The effectiveness of the novel intervention was estimated from the trial's outcomes, 7-day abstinence and smoking reduction by half. We assumed that reducing cigarette consumption by half would lead to sustained abstinence for $15 \%$ of the reducers, ${ }^{29-32}$ while all quitters were assumed to maintain abstinence. On the population level, the change in smoking prevalence was calculated by multiplying the proportion of quitters due to the intervention by the number of smokers seeking dental care each year. In the health economic evaluation, we assume that the estimated quitters will be continuously abstinent after the study's end (6-month follow-up).

\section{Population-based simulation model}

We simulated the impact of changes in incidence of and related societal costs for several chronic diseases during 10 years, following the assumed changes in smoking prevalence because of the interventions in the Swedish population 20-84 years old in 2014. A model that incorporates four lifestyles factors, denominated 'Risk factors, health and societal costs', ${ }^{3,}$ was used, with only the smoking domain estimates employed for this study. The model simulates effects on health outcomes associated with smoking, including diabetes mellitus type 2, ischaemic heart disease, ischaemic and haemorrhagic stroke, COPD and cancer of the lung, oesophagus, liver, larynx, stomach, pancreatic, colon and rectum.

The model uses a modified version of the potential impact fraction, ${ }^{3435}$ where the intervention effect changed the relative risk (RR) of disease of the exposed category (smokers), while keeping the prevalence of exposed category constant. In our case, the RR changes for smokers when some of them quit.

$$
P I F=\frac{\mathrm{Ps} * \mathrm{RRs}-\mathrm{Ps} * \mathrm{RRs}{ }^{\prime}}{\mathrm{Ps} * \mathrm{RRs}}
$$

where:

Ps is the prevalence of smoking,

RRs is the relative risk of disease associated with smoking,

$\mathrm{RRs}^{\prime}$ is the changed relative risk of disease after the intervention when a part of smokers have quit.

The incidence rate of the disease after this change in the related risk factor $\left(\mathrm{I}^{\prime}\right)$ becomes:

$$
\mathrm{I}^{\prime}=\mathrm{I} *(1-\mathrm{PIF})
$$

where is the original incidence rate.

The RRs for smokers compared with non-smokers were estimated from epidemiological studies, as presented in the technical report, ${ }^{33}$ and additionally ischaemic heart disease, ischaemic and haemorrhagic stroke ${ }^{36-39} \mathrm{COPD}^{40}{ }^{41}$ and different cancers. ${ }^{42} 43$ The changing RRs'were calculated for every year and every disease, based on the decrease in risks for ex-smokers over time. For ischaemic heart disease, stroke, COPD and lung cancer, we used the estimations presented in Hurley and Matthews. ${ }^{44}$ We assumed that risks for ex-smokers for diabetes mellitus follow the pattern of CVD decrease while the risks for other cancer diagnoses decrease linearly during 20 years. The QALY weights were used to describe the losses in health-related quality of life (QoL) due to the diseases. The weights are community based, derived via the EuroQol (EQ)-5D classification system with the UK time-trade-off valuations. ${ }^{45}$ The time horizon is 10 years so the economic and health gains were calculated based on decreased incidence of the diseases during 10 years. The societal costs include medical treatment costs and municipal costs for care; hence, the model adopted a limited societal perspective as patient and productivity costs are not included. Swedish national registers were used to retrieve disease incidence and disease-specific medical care costs, while municipal care 
costs were estimated via a Swedish study. The model was developed in Excel (Microsoft Office, 2010); details of the model are published in a technical report. ${ }^{33}$

\section{Markov model}

A Markov model was used to estimate health consequences and societal costs of smoking cessation. ${ }^{46}$ The model has been used in similar studies in Sweden ${ }^{144}$ and was updated for the purpose of the current analysis. The model simulates the societal effects of quitting smoking on three diseases: lung cancer, COPD and CVD, including coronary heart disease and stroke. The model incorporates the smoking-related disease risks, time-dependent remaining excess disease risks after quitting, the death risks for the specific and for unrelated diseases, as well as the societal effects of the three diseases. All disease risks are annual age- and gender-specific excess incidence until death or the age of 95 years. The societal costs include costs associated to medical treatment, municipal costs for care, drugs, informal care and other expenditures for patients and relatives as well as morbidity productivity costs. Health outcomes are expressed in QALYs. The number of QALYs were calculated during healthy years and years spent diseased, until death or the age of 95 years. Swedish average age- and gender specific QoL weights were used for healthy years. ${ }^{48}$ For years with disease, disease-specific QoL decrements taken from international studies were deducted from the average QoL.

Most of the societal costs were derived from Swedish studies published during the 2010s and were reported as distributions, that is, with the gamma parameters or bootstrapped $95 \%$ CI, in order to enable stochastic estimation.

The Markov stages are 1 year long, with no half-cycle correction. The probabilistic model is run as a microsimulation with 10000 repetitions. The Markov cycle tree was created in Treeage Pro (Treeage, 2015). Details on the model are available from a technical report. ${ }^{46}$

\section{Sensitivity analyses}

Several one-way sensitivity analyses were conducted to test the robustness of the results. First, we examined the effect of changing the assumptions about the proportion of smokers assumed to achieve permanent abstinence after reducing consumption by half to (1) $5 \%$ and (2) $25 \%$. Second, we examined the effect of changing the assumption of intervention coverage of dental care patients to $70 \%$. Third, we included the full training costs into the intervention costs.

To illustrate the correspondence between the two models and to increase understanding of the comparisons, a detailed calculation restricted to one gender and age group was performed with the same time frame (10 years), using only the healthcare perspective.

\section{RESULTS}

\section{Intervention costs}

Table 1 shows the costs of the interventions. Most of the interventions' costs could be attributed to the use of NRT and other medications.
Total cost for the brief advice was estimated at US $\$ 56$ per smoker, and the difference in costs between the intervention and 'usual care' was US\$6.5. The cost per quitter was US\$552 in the intervention and US\$522 in the "usual care' condition. If delivered to all Swedish smokers visiting dental care every year, the total costs would be US $\$ 25.0$ million per year for the alternative intervention and US\$22.1 million for 'usual care'.

\section{Intervention effectiveness}

Ten smokers (four men and six women) could be expected to quit in 'usual care' condition, compared with10 smokers (only women) in the intervention condition.

When the effects were applied to the entire population, the prevalence of smoking among men was projected to decrease from $8.9 \%$ to $8.8 \%$ for the novel intervention and to $8.3 \%$ for 'usual care'. The prevalence of smoking among women would decrease from $11.6 \%$ to $10.5 \%$ for intervention and to $10.8 \%$ for 'usual care'. The estimations of effectiveness are presented in table 2.

\section{Cost-effectiveness analyses}

Model outputs and cost-effectiveness analyses are presented in table 3, with a detailed example given for women aged 45-64 years in table 4 .

\section{Markov model}

The gains associated with the novel intervention resulted in societal savings of US $\$ 77000$, including savings of US $\$ 32000$ in healthcare and 5.42 QALYs. For 'usual care', the gains were societal savings of US\$60000, including savings of US $\$ 26000$ in healthcare and 4.74 QALYs. Also including the intervention costs, the net societal savings were US\$72100 for the intervention and US\$57800 for the 'usual care' group, with associated gains in QALYs, 5.42 for the intervention and 4.74 for 'usual care' during the lifetime. According to this model, the brief intervention was dominant, entailing cost saving and additional health gain of 0.68 QALYs.

\section{Population-based model}

The brief intervention applied to smokers showed a total societal saving of US $\$ 42.3$ million, of which US $\$ 27.6$ million were savings in healthcare costs, and a gain of 1428 QALYs for the full Swedish population 20-84 years old during 10 years. The corresponding estimates for 'usual care' demonstrated a total societal savings of US $\$ 72.0$ million, out of which US $\$ 46.9$ million were savings in healthcare costs, and a gain of 2369 QALYs for the full Swedish population 20-84 years old during 10 years. When both intervention costs and estimated societal savings are considered, the net societal saving was US $\$ 17.3$ million for the brief advice and US $\$ 49.9$ million for 'usual care', with health gains as above. Thus, the brief novel counselling was more expensive and less effective, so-called dominated by the 'usual care' alternative, according to the population-based model. 
Table 1 Intervention costs, in 2014 (US\$)

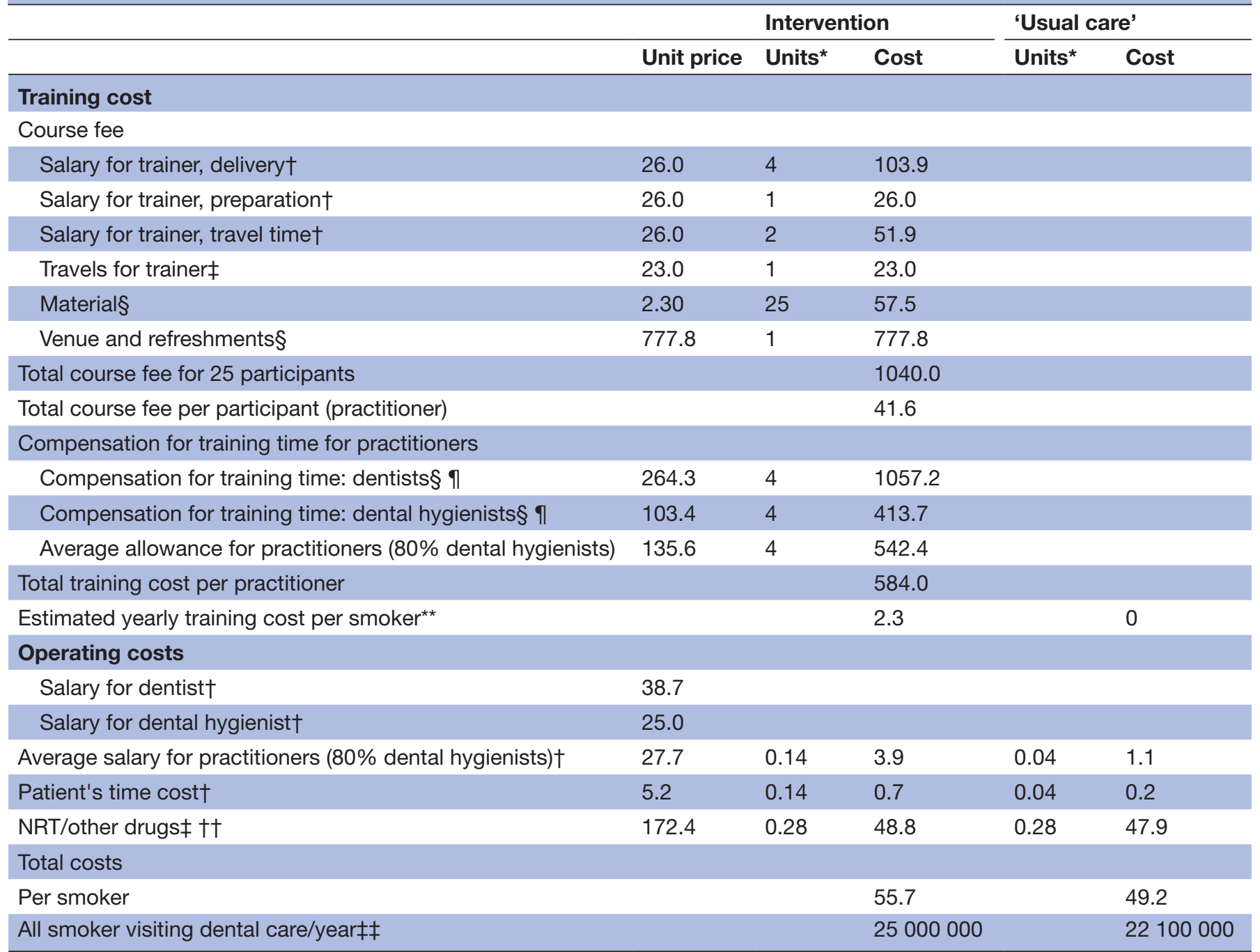

*Hours or number.

†Information on average salaries from Statistics Sweden: www.scb.se ‡Based on information from suppliers' websites.

$\S$ Based on the study records or information from training organisers.

ףIncludes loss of revenue.

**Estimated yearly number of smokers visiting a dental practitioner: 50 .

††Proportion (units) based on information from the trial.

¥†Estimated by costs/smoker $\times$ number of adults visiting dental care each year $(n=449000)$.

NRT, nicotine replacement therapy.

\section{Sensitivity analyses}

When the proportions assumed to achieve abstinence after reducing by half were set to $5 \%$ or to $25 \%$, the magnitude of the difference between two models remained. As with the main analysis, the population-based model favoured 'usual care' over the novel intervention, while the Markov model favoured this latter over 'usual care'. Likewise, when the coverage of the brief advice or of 'usual care' was assumed to be $70 \%$, the gains decreased, but the patterns of difference were similar to the main analysis. When including all training costs into the intervention costs, the results were almost similar to the main analysis.

In order to illustrate the correspondence between the population-based and Markov model, separate calculations were restricted to women in age group 45-64 years, using
10 years' time horizon and only the healthcare perspective. The estimates from the population-based model for this group show cost savings for healthcare sector of US $\$ 598$ per quitter. The healthcare savings estimated with the Markov model for the same group during 10 years were US $\$ 547$ per quitter. In essence, for this group, both models show the same level of cost saving for a quitter as well as the same level of health gains (0.02 vs 0.03 QALYs).

\section{DISCUSSION}

In this case study, the cost-effectiveness of a brief manualised counselling for smoking cessation in dentistry was assessed using two different models: a population-based model comparing different scenarios of smoking 
Table 2 Effectiveness estimation

\section{Intervention}

\section{'Usual care'}

\begin{tabular}{lllllll}
\hline Age & $20-44$ & $45-64$ & $65-84$ & $20-44$ & $45-64$ & $65-84$ \\
Participants in the FRITT study $(\mathrm{n})$ & & & & & \\
Men & 11 & 20 & 2 & 9 & 20 & 9 \\
Women & 19 & 41 & 6 & 20 & 37 & 11
\end{tabular}

Reduced cigarette consumption by half $(n)^{\star}$

$\begin{array}{llllllll}\text { Men } & 2 & 2 & 0 & 1 & 2 & 0 \\ \text { Women } & 5 & 9 & 1 & 2 & 4 & 0 \\ \text { Quitters (n) } & & & & & & \\ \text { Men } & 0 & 0 & 0 & 1 & 1 & 1 & 3\end{array}$

Effectiveness data, estimated quitters (n)-used in Markov model†

\begin{tabular}{|c|c|c|c|c|c|c|}
\hline Men & 0 & 0 & 0 & 1 & 2 & 1 \\
\hline Women & 3 & 6 & 1 & 1 & 2 & 3 \\
\hline \multicolumn{7}{|c|}{ Proportion of estimated quitters (\%) } \\
\hline Women & 14 & 15 & 19 & 7 & 4 & 27 \\
\hline \multicolumn{7}{|c|}{ Swedish population (n) } \\
\hline Women & 1561289 & 1205769 & 867493 & 1561289 & 1205769 & 867493 \\
\hline \multicolumn{7}{|c|}{ Smokers in Sweden (n) } \\
\hline Men & 114090 & 147395 & 63113 & 114090 & 147395 & 63113 \\
\hline Women & 124903 & 192923 & 104099 & 124903 & 192923 & 104099 \\
\hline \multicolumn{7}{|c|}{ Smokers who visit dental care each year (n) } \\
\hline Men & 6.90 & 11.88 & 8.00 & 6.55 & 11.10 & 7.42 \\
\hline Women & 7.42 & 14.39 & 10.51 & 7.74 & 15.55 & 9.87 \\
\hline
\end{tabular}

${ }^{*}$ Results from FRITT study.

†Calculated as $15 \%$ of the 'Reduced cigarette consumption by half' plus 'Quitters'.

$\ddagger$ Calculated as '(number of smokers in Sweden-(proportion of estimated quitters $\times$ smokers who visit dental care each year))/ Swedish population in the age and sex group'.

prevalence and a Markov model estimating the outcomes for the quitters. A similar population-based model was presented in Magnus et $a l,{ }^{49}$ while a similar Markov model was presented in Hurley and Matthews. ${ }^{44}$

The original trial did not show any significant effect on smoking cessation of the novel intervention compared to usual treatment in a sample of smokers not selected according to their motivation to quit. The alternative intervention's costs were low, under US $\$ 60$ per patient, and the incremental cost compared with 'usual care' was less than US $\$ 7$ per patient. In the intervention condition, the cost per quitter was only slightly higher than in the control condition, and it compares favourably to the estimated cost per quitter in other smoking cessation studies.

Nevertheless, the comparison of the economic effects between the intervention and 'usual care' favoured the latter when modelling the population impact. In contrast, using the outcomes for the quitters in a Markov model showed that the intervention was preferable to "usual care', resulting in net societal cost savings and some gain in QALYs.

The difference in results with the two modelling strategies could be expected, in the first place because they differ in several aspects of model specification. The population-based model only considers healthcare costs and municipal costs for care, while the Markov model also considers cost for medications, costs for patients and relatives and morbidity productivity costs. The time frame was also different, that is, 10 years for the population-based model and lifetime for the Markov model. Finally, there were differences in the number of diseases included. However, as the comparison by cost category in 
Table 3 Model outputs: Markov and population-based models (costs in thousand US\$2014)

\begin{tabular}{|c|c|c|c|c|c|c|c|c|c|}
\hline & \multicolumn{3}{|c|}{ Intervention } & \multicolumn{3}{|c|}{ 'Usual care' } & \multicolumn{2}{|c|}{$\begin{array}{l}\text { ICER (intervention vs } \\
\text { 'usual care') }\end{array}$} & \multirow[t]{2}{*}{ Conclusion } \\
\hline & Female & Male & Total & Female & Male & Total & $\begin{array}{l}\text { Diff } \\
\text { QALY }\end{array}$ & Diff costs & \\
\hline \multicolumn{10}{|l|}{ Markov model } \\
\hline Intervention costs & & & 4.9 & & & 5.2 & & & \\
\hline Cost savings & -77 & 0 & -77 & -31 & -32 & -63 & & & \\
\hline Net costs & & & -72.1 & & & -57.8 & & & \\
\hline \multirow[t]{2}{*}{ QALYs } & 5.42 & 0 & 5.42 & 2.37 & 2.36 & 4.74 & & & \\
\hline & & & & & & & 0.68 & -14.3 & Dominant \\
\hline \multicolumn{10}{|l|}{ Population model } \\
\hline Intervention costs & & & 25000 & & & 22100 & & & \\
\hline Cost savings & -39562 & -2756 & -43318 & -34854 & -37125 & -71979 & & & \\
\hline Net costs & & & -18318 & & & -49879 & & & \\
\hline \multirow[t]{2}{*}{ QALYs } & 1327.8 & 100.4 & 1428.2 & 1117.1 & 1252.2 & 2369.3 & & & \\
\hline & & & & & & & -941.1 & 31561 & Dominated \\
\hline
\end{tabular}

Diff, difference; ICER, incremental cost-effectiveness ratio; QALY, quality-adjusted life-year.

table 4 shows, the magnitude of costs is similar for both models.

The opposite conclusions from the two models are probably best explained by the difference in the population to which the simulation is applied. In fact, the population-based model estimates the effect of the intervention brought to the entire population of smokers in Sweden, while the Markov model simulates individual effects for the quitters in the study cohort. Quitters in the intervention group were in average younger than in the 'usual care' group and all of them were women, while the gender distribution of quitters was more balanced in the 'usual care' group. Thus, the Markov model shows greater gains in QALYs and societal savings for the alternative intervention due to longer time horizon for younger age groups. In contrast, the population-based model converts the trial outcomes to age- and gender-specific population prevalence.

The modelling strategies inherent in the two models explain why the cost-effectiveness results differ between the models. Population-based models simulate how changes in prevalence of risk factors affect the disease incidence over age- and gender-specific groups. The individual-based Markov models simulate the changes in disease incidence because of changes in risk factors in a specific, albeit hypothetical, individual of a certain age and gender. In population-based models, groups with a high disease incidence affect the estimates more than groups where the incidence is lower at the start of the simulation. In this study, the four male quitters in the control group affected the result disproportionally, in particular as there were no male quitters in the alternative intervention group. Small trials with few participants and, more importantly, few successful participants are not likely to represent the population to which the interventions are to be applied, thus skewing the estimates in population-based models.

The weaknesses in both strategies of economic evaluations include non-significant differences in the effectiveness of the novel intervention compared with the control condition. Furthermore, some assumptions about the proportion of reducers eventually quitting or about all quitters achieving sustained abstinence may not be tenable and thus contribute to increase the uncertainty of the estimates.

Table 4 Model outputs in the subgroup of women 45-64 years: Markov and population-based models, 10 years' time horizon, healthcare perspective (costs in 2014 US\$)

\begin{tabular}{|c|c|c|c|}
\hline & Intervention effect & Healthcare cost & QALYs \\
\hline \multicolumn{4}{|l|}{ Markov model } \\
\hline Per quitter & 1 & 547 & 0.02 \\
\hline Intervention & $\begin{array}{l}\text { Change in prevalence: } 1.61 \% \\
\text { Quitters (n): } \\
19422\end{array}$ & $\begin{array}{l}-11607004 \\
\text { Per quitter: } \\
-598\end{array}$ & $\begin{array}{l}604.94 \\
\text { Per quitter: } \\
0.03\end{array}$ \\
\hline
\end{tabular}


To our knowledge, this is the first study to compare different health economic strategies to estimate the cost-effectiveness of a brief advice for smoking cessation in dental clinics in Sweden. The combination and comparison of two different approaches for the estimation of cost-effectiveness is an original contribution providing insights on factors to be considered in decision making about large-scale dissemination of an intervention. In this regard, we offer the general recommendation to avoid the estimation of cost-effectiveness with population-based models from small-scale trials with skewed effectiveness across participant groups.

Contributors All authors made substantial contributions to the paper. Specifically, SEV analysed data, drafted and revised the paper.

Funding This work was supported by the Swedish National Board of Health and Welfare contract grant number 2.4-43860/2011 and with research and development funds from the Stockholm County Council. The funders had no role in study design; collection, analysis, and interpretation of data; writing the report; or in the decision to submit the paper for publishing.

Competing interests All authors have completed the ICMJE uniform disclosure form at www.icmje.org/coi_disclosure.pdf and declare the following: SV reports grants from The National Board of Health and Welfare, during the conduct of the study, and personal fees from The National Board of Health and Welfare, outside the submitted work; PJ reports grants from The National Board of Health and Welfare, during the conduct of the study; MG reports grants from The National Board of Health and Welfare and personal fees from The Stockholm County Council, during the conduct of the study, and personal fees from The Stockholm County Council and grants from Public Health Agency of Sweden and from FORMAS, outside the submitted work; IF has nothing to disclose.

Provenance and peer review Not commissioned; externally peer reviewed.

Data sharing statement № additional data available.

Open Access This is an Open Access article distributed in accordance with the Creative Commons Attribution Non Commercial (CC BY-NC 4.0) license, which permits others to distribute, remix, adapt, build upon this work non-commercially, and license their derivative works on different terms, provided the original work is properly cited and the use is non-commercial. See: http://creativecommons.org/ licenses/by-nc/4.0/

(C) Article author(s) (or their employer(s) unless otherwise stated in the text of the article) 2017. All rights reserved. No commercial use is permitted unless otherwise expressly granted.

\section{REFERENCES}

1. Institute for Health Metrics and Evaluation. Country profiles: Sweden. http://www.healthdata.org/sweden (accessed 5 Nov 2015).

2. Bolin K, Lindgren B. Smoking, healthcare cost, and loss of productivity in Sweden 2001. Scand J Public Health 2007;35:187-96.

3. Doll R, Peto R, Boreham J, et al. Mortality in relation to smoking: 50 years' observations on male british doctors. BMJ 2004;328:1519.

4. Eyre H, Kahn R, Robertson RM, et al.Preventing cancer, cardiovascular disease, and diabetes: a common agenda for the American Cancer Society, the American Diabetes Association, and the American Heart Association. CA Cancer J Clin 2004;54:190-207.

5. Deloukas P, Kanoni S, Willenborg C, et al.Large-scale association analysis identifies new risk loci for coronary artery disease. Nat Genet 2013;45:25-33.

6. The National Board of Health and Welfare. Nationella riktlinjer för sjukdomsförebyggande metoder. Tobaksbruk, riskbruk av alkohol, otillräcklig fysisk aktivitet och ohälsosamma matvanor, 2011.

7. Socialstyrelsen. Befolkningens tandhälsa 2009: Socialstyrelsen, 2010.

8. SBU. Rökning och ohälsa i munnen: Statens beredning för medicinsk utvärdering, 2002.

9. Curry SJ. Building effective strategies to decrease tobacco use in a health maintenance organisation: Group Health Cooperative of Puget Sound. Tob Control 1998;7(Suppl 1):S21-S23.

10. Katz DA, Muehlenbruch DR, Brown RL, et al. Effectiveness of implementing the agency for healthcare research and quality smoking cessation clinical practice guideline: a randomized, controlled trial. J Natl Cancer Inst 2004;96:594-603.

11. Fiore MC, Jaén CR, Baker TB, et al. Treating tobacco use and dependence: 2008 Update Clinical Practice Guideline. Rockville, MD: U.S. Department of Health and Human Services, Public Health Service, 2008.

12. West R, Raw M, McNeill $A$, et al. Health-care interventions to promote and assist tobacco cessation: a review of efficacy, effectiveness and affordability for use in national guideline development. Addiction 2015;110:1388-403.

13. Ekpu VU, Brown AK. The economic impact of smoking and of reducing smoking prevalence: review of evidence. Tob Use Insights 2015;8:1-35.

14. Nohlert E, Helgason AR, Tillgren $P$, et al. Comparison of the costeffectiveness of a high- and a low-intensity smoking cessation intervention in Sweden: a randomized trial. Nicotine Tob Res 2013;15:1519-27.

15. Nasser M. Evidence summary: is smoking cessation an effective and cost-effective service to be introduced in NHS dentistry? Br Dent $J$ 2011;210:169-77.

16. Bolin K. Economic evaluation of smoking-cessation therapies: a critical and systematic review of simulation models. Pharmacoeconomics 2012;30:551-64.

17. Howard $P$, Knight $C$, Boler A, et al. Cost-utility analysis of varenicline versus existing smoking cessation strategies using the BENESCO simulation model: application to a population of US adult smokers. Pharmacoeconomics 2008;26:497-511.

18. Knight C, Marbaix S, Annemans L, et al. The cost-effectiveness of an extended course $(12+12$ weeks) of varenicline plus brief counselling compared with other reimbursed smoking cessation interventions in Belgium, from a public payer perspective. Acta Clin Belg 2012;67:416-22.

19. Parrott S, Godfrey C, Raw M, et al. Guidance for commissioners on the cost effectiveness of smoking cessation interventions. Health Educational Authority. Thorax 1998;53(Suppl 5 Pt 2):S1-38.

20. Ratcliffe J, Cairns J, Platt S. Cost effectiveness of a mass media-led anti-smoking campaign in Scotland. Tob Control 1997;6:104-10.

21. Virtanen SE, Zeebari Z, Rohyo I, et al. Evaluation of a brief counseling for tobacco cessation in dental clinics among swedish smokers and snus users. A cluster randomized controlled trial (the FRITT study). Prev Med 2015;70:26-32.

22. Lee PN. Epidemiological evidence relating snus to health-an updated review based on recent publications. Harm Reduct $J$ 2013;10:36.

23. The dental and Pharmaceutical Benefits Agency (TLV) . General guidelines for economic evaluations from the Pharma-ceutical Benefits Board (LFNAR 2003:2). Stockholm, Sweden: The Dental and Pharmaceutical Benefits Agency, 2003. http://www.tlv.se/Upload/ English/Guidelines-for-economic-evaluations-LFNAR-2003-2.pdf (accessed 25 Nov 2015).

24. Statistics Sweden. Konsumentprisindex. 2016. http://www.scb.se/ pr0101/ (accessed 14 Apr).

25. Sampaio F, Enebrink P, Mihalopoulos C, et al. Cost-effectiveness of four parenting programs and bibliotherapy for parents of children with conduct problems. J Ment Health Policy Econ 2016;19:201-12.

26. Wellander L, Wells MB, Feldman I. Does prevention pay? Costs and potential cost-savings of school interventions targeting children with mental health problems. J Ment Health Policy Econ 2016;19:91-101.

27. Public Health Agency of Sweden.. Tobaksvanor - Nationella resultat och tidsserier 2015 [Tobacco Use Habits - National Results and Time Series 2015]. 2015. http://www.folkhalsomyndigheten. se/amnesomraden/statistik-och-undersokningar/enkater-ochundersokningar/nationella-folkhalsoenkaten/levnadsvanor/ tobaksvanor/

28. Jacobs $\mathrm{P}$, Fassbender $\mathrm{K}$. The measurement of indirect costs in the health economics evaluation literature. A review. Int J Technol Assess Health Care 1998:14:799-808.

29. Hyland A, Levy DT, Rezaishiraz $\mathrm{H}$, et al. Reduction in amount smoked predicts future cessation. Psychol Addict Behav 2005; 19:221-5.

30. Farkas AJ. When does cigarette fading increase the likelihood of future cessation? Ann Behav Med 1999;21:71-6.

31. Falba $\mathrm{T}$, Jofre-Bonet $\mathrm{M}$, Busch $\mathrm{S}$, et al. Reduction of quantity smoked predicts future cessation among older smokers. Addiction 2004;99:93-102.

32. Broms U, Korhonen T, Kaprio J. Smoking reduction predicts cessation: longitudinal evidence from the Finnish adult twin cohort. Nicotine Tob Res 2008;10:423-7. 
33. Feldman I, Johansson P. The swedish RHS-model (Risk factors, health and societal costs). Technical Report 2014 www.hfsnatverket. se.

34. Morgenstern H, Bursic ES. A method for using epidemiologic data to estimate the potential impact of an intervention on the health status of a target population. J Community Health 1982;7:292-309.

35. Barendregt JJ, Veerman JL. Categorical versus continuous risk factors and the calculation of potential impact fractions. J Epidemiol Community Health 2010;64:209-12.

36. Niølstad I, Arnesen E. Preinfarction blood pressure and smoking are determinants for a fatal outcome of myocardial infarction: a prospective analysis from the Finnmark Study. Arch Intern Med 1998;158:1326-32.

37. Stamler J, Dyer AR, Shekelle RB, et al. Relationship of baseline major risk factors to coronary and all-cause mortality, and to longevity: findings from long-term follow-up of Chicago cohorts. Cardiology 1993;82:191-222.

38. Group MR. Relationship between baseline risk factors and coronary heart disease and total mortality in the multiple risk factor intervention trial. multiple risk factor intervention trial research group. Prev Med 1986;15:254-73.

39. Robbins AS, Manson JE, Lee IM, et al. Cigarette smoking and stroke in a cohort of U.S. male physicians. Ann Intern Med 1994;120:458-62.

40. Lindberg A, Sawalha S, Hedman L, et al. Subjects with COPD and productive cough have an increased risk for exacerbations and death. Respir Med 2015;109:88-95.
41. Lindberg A, Lundbäck B. [Underdiagnosed disease with high mortality. prevalence of COPD is strongly related to smoking habits and increasing age]. Lakartidningen 2007;104:1032-4.

42. Kuper H, Boffetta P, Adami HO. Tobacco use and cancer causation: association by tumour type. J Intern Med 2002;252:206-24.

43. Colditz GA, Atwood KA, Emmons K, et al. Harvard report on cancer prevention volume 4: Harvard Cancer Risk Index. Risk Index Working Group, Harvard Center for Cancer Prevention. Cancer Causes Control 2000;11:477-88.

44. Hurley SF, Matthews JP. The quit benefits model: a Markov model for assessing the health benefits and health care cost savings of quitting smoking. Cost Eff Resour Alloc 2007;5:2.

45. Sullivan PW, Slejko JF, Sculpher MJ, et al. Catalogue of EQ-5D scores for the United Kingdom. Med Decis Making 2011;31:800-4.

46. Johansson. A model for economic evaluations of smoking cessation interventions - technical report. Model version 3: Folkhälsa \& Ekonomi (Public Health \& Economics), 2015.

47. Johansson PM, Tillgren PE, Guldbrandsson KA, et al. A model for cost-effectiveness analyses of smoking cessation interventions applied to a quit-and-win contest for mothers of small children. Scand J Public Health 2005;33:343-52.

48. Burström K, Johannesson M, Diderichsen F. Health-related quality of life by disease and socio-economic group in the general population in Sweden. Health Policy 2001;55:51-69.

49. Magnus A, Cadilhac D, Sheppard L, et al. Economic benefits of achieving realistic smoking cessation targets in Australia. Am J Public Health 2011;101:321-7. 